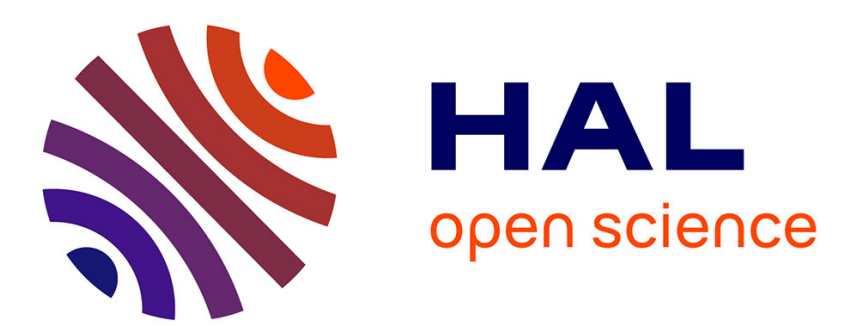

\title{
Non-thermal effect on densification kinetics during microwave sintering of alpha-alumina
}

Fei Zuo, Sébastien Saunier, Christophe Meunier, Dominique Goeuriot

\section{To cite this version:}

Fei Zuo, Sébastien Saunier, Christophe Meunier, Dominique Goeuriot. Non-thermal effect on densification kinetics during microwave sintering of alpha-alumina. Scripta Materialia, 2013, 69 (4), pp.331-333. 10.1016/j.scriptamat.2013.05.016 . emse-01063760

\section{HAL Id: emse-01063760 \\ https://hal-emse.ccsd.cnrs.fr/emse-01063760}

Submitted on 27 Aug 2021

HAL is a multi-disciplinary open access archive for the deposit and dissemination of scientific research documents, whether they are published or not. The documents may come from teaching and research institutions in France or abroad, or from public or private research centers.
L'archive ouverte pluridisciplinaire HAL, est destinée au dépôt et à la diffusion de documents scientifiques de niveau recherche, publiés ou non, émanant des établissements d'enseignement et de recherche français ou étrangers, des laboratoires publics ou privés. 


\title{
Non-thermal effect on densification kinetics during microwave sintering of $\alpha$-alumina
}

\author{
F. Zuo, S. Saunier, ${ }^{*}$ C. Meunier and D. Goeuriot \\ Centre Sciences des Matériaux et des Structures, CNRS-UMR 5307, Ecole Nationale Supérieure des Mines de Saint-Etienne, \\ 158 cours Fauriel, 42023 St-Etienne, France
}

\begin{abstract}
The microstructural evolution and densification kinetics of $\alpha$-alumina were investigated and compared between conventional sintering and microwave sintering at $2.45 \mathrm{GHz}$ in the intermediate stage, where the microwave seems to be the most efficient. Based on classical kinetics models, the calculated kinetics parameter demonstrated that the densification is greatly influenced by the presence of an electromagnetic field during sintering. It was assumed that the grain boundary diffusion is enhanced by an electromagnetic pressure induced by the microwave.
\end{abstract}

Keywords: Sintering; Kinetics; Grain growth; Electromagnetic pressure

In recent decades, many researchers reported applications of microwave energy to sinter alumina [1-3]. It is well known that microwave sintering results in a higher heating rate and a lower sintering time compared with conventional sintering. This enhanced densification was usually regarded as a specific action of microwaves on mass transport in crystalline solids, socalled "microwave ponderomotive effect" [4]. Experimental results demonstrated a lower activation energy in the case of microwave sintering vs. conventional sintering of alumina $[5,6]$. This is in favor of microwave enhancement from the viewpoint of kinetics. However, the mechanistic difference in this enhanced effect is still questionable.

The goals of the present work were to clarify the nonthermal effect of microwave sintering on alumina. Based on a recent study comparing the microwave and conventional sintering of alumina [7], the densification kinetics in the intermediate stage of sintering, where the microwave effect was mostly activated, were investigated. The investigation was set to compare the microstructural evolution of alumina under these two methods of heating and to formulate hypotheses about the diffusion mechanisms controlling the intermediate stage of microwave sintering.

\footnotetext{
* Corresponding author. Tel.: +33 477 420225; fax: +33 477 420249; e-mail: saunier@emse.fr
}

The starting material was high-purity commercial $\alpha-\mathrm{Al}_{2} \mathrm{O}_{3}$ powder $(>99.99 \%$, BWP-15, Baikowski International, France) with a specific surface area of $19 \mathrm{~m}^{2} \mathrm{~g}^{-1}$. It was uniaxially pressed into disks $(12 \mathrm{~mm}$ in diameter by $4 \mathrm{~mm}$ thick for microwave sintering and $8 \mathrm{~mm}$ in diameter by $4.5 \mathrm{~mm}$ thick for conventional sintering) at $390 \mathrm{MPa}$ for microwave sintering or at $400 \mathrm{MPa}$ for conventional sintering, in order to achieve a similar green density. The binder was removed by heating at $2{ }^{\circ} \mathrm{C} \mathrm{min}$ m $^{-1}$ to $600{ }^{\circ} \mathrm{C}$ with a dwell time of $1 \mathrm{~h}$ in air, and weight losses after binder removal were $\sim 1.7 \%$. The average density of green bodies after debinding was $52.3 \pm 0.2 \%$ of total density (TD).

The microwave sintering experiments were performed in a $3 \mathrm{~kW}, 2.45 \mathrm{GHz}$ multimode microwave cavity (SAIREM, France). The configuration of this heating and measuring system was reported by Zuo et al. [7]. This system makes possible the in situ measurement of the shrinkage during sintering. Conventional sintering was carried out in air, using a dilatometer (Setsys 16/18, SETARAM, France). For non-isothermal sintering, a heating rate of $25^{\circ} \mathrm{C} \mathrm{min}^{-1}$ was used to reach $1550{ }^{\circ} \mathrm{C}$, with a holding time of $5 \mathrm{~min}$, which is a common thermal cycle for both sintering methods. Moreover, a high heating rate of $100{ }^{\circ} \mathrm{C} \mathrm{min}^{-1}$ and a low one of $1.6^{\circ} \mathrm{C} \min ^{-1}$ were chosen for microwave and conventional sintering at 1420 and $1290^{\circ} \mathrm{C}$, respectively. Isothermal sintering kinetics were investigated from 1000 to $1300{ }^{\circ} \mathrm{C}$ for microwave sintering and only at 
$1250^{\circ} \mathrm{C}$ for conventional sintering, with a heating rate of 100 and $25^{\circ} \mathrm{C} \mathrm{min}^{-1}$, respectively, and with different dwell durations.

Densities and densification rate were calculated from the final densities measured by Archimedes' method and from the recorded shrinkage data. The average grain size for each sintered sample was observed by scanning electron microscopy (JSM-6500F, JEOL, Japan). It was measured by the intercepts method on at least 250 grains on fractured surfaces. A statistical correction factor of 1.56 was applied to the measured apparent grain size [8].

The density and densification rate curves of alumina under microwave and conventional non-isothermal sintering are shown in Figure 1. According to the density curves, for a given temperature during sintering, the density of the microwave-sintered sample is higher than that of the conventionally sintered sample. A similar phenomenon has been observed among the densification rate curves. Microwave heating promotes the densification of the samples at a higher rate, and then reaches the top densification rate at $1293{ }^{\circ} \mathrm{C}$, which is $46^{\circ} \mathrm{C}$ lower than that obtained during conventional heating. These phenomena provide a strong verification of the microwave effect in the case of $\mathrm{Al}_{2} \mathrm{O}_{3}$ sintering. Furthermore, the curves clearly show that, beyond a rising stage, the difference between the two sintering processes gradually reduced at the high temperature stage. This means that the microwave enhancement mostly acts in the intermediate stage of the sintering process. This result is in good agreement with the literature [7]. Thus, the densification kinetics have been investigated in the intermediate stage.

To study the densification kinetics of isothermal sintering, Coble's geometrical model of intermediate stage sintering was used [9]. Based on this model, the relative densification rate can be written as [10]:

$\frac{1}{\rho} \frac{d \rho}{d t} \propto \frac{D_{1} \gamma_{\mathrm{s}} V_{\mathrm{m}}}{R T G^{3}} . \quad$ (densification by lattice diffusion)

or

$\frac{1}{\rho} \frac{d \rho}{d t} \propto \frac{D_{\mathrm{b}} \delta_{\mathrm{b}} \gamma_{\mathrm{s}} V_{\mathrm{m}}}{R T G^{4}} \quad$ (densification by grain boundary diffusion)

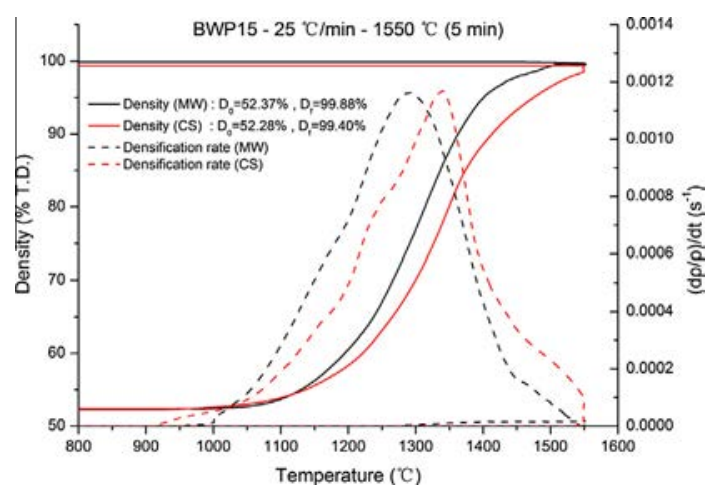

Figure 1. Densification curves of $15 \mathrm{~m}^{2} \mathrm{~g}^{-1} \mathrm{Al}_{2} \mathrm{O}_{3}$ powder during microwave (MW) and conventional (CS) sintering at a heating rate of $25^{\circ} \mathrm{C} \min ^{-1}$. where $D_{1}$ is the lattice diffusion coefficient, $\gamma_{\mathrm{s}}$ is the specific surface energy of the solid, $V_{\mathrm{m}}$ is the molar volume of the solid, $D_{\mathrm{b}}$ is the grain boundary diffusion coefficient, $\delta_{\mathrm{b}}$ is the diffusion thickness of grain boundary diffusion, $G$ is the grain size, $R$ is the Boltzmann constant, and $T$ is the absolute temperature. In order to determine the dominant diffusion mechanism controlling the densification, the interrelationship between grain size and relative density of a sample is necessary. This sintering trajectory before the final stage is shown in Figure 2.

According to Figure 2, the plots follow a single path, which means that there is no noticeable difference in the grain growth trajectory for samples sintered by different thermal sources or cycles. The intrinsic driving force of sintering is the reduction in the total interfacial energy. The same grain size evolution, depending on the density, corresponds to the same intrinsic driving force for conventionally sintered and microwave-sintered samples throughout densification. As a result, the enhanced densification process under an electromagnetic field should benefit from enhanced diffusion, corresponding to the existence of an external driving force for sintering.

By means of the interrelationship between grain size and density, the densification kinetics results are given in Figure 3.

For this continuous calculation, the relative density ranged between $70 \%$ and $90 \%$ TD $(70-85 \%$ TD for $1200{ }^{\circ} \mathrm{C}$ ), corresponding to the intermediate stage of sintering. By observing each curve, it can be seen that the plots may be approximated using a linear equation. The derived slopes $n$ are noted beside the curves in Figure 3.

According to this analysis, densification of alumina during the intermediate stage of conventional sintering seems to be predominantly controlled by grain boundary diffusion (Fig. 3B, $n \approx 4$ ). This result is in good agreement with the literature [11]. Compared with conventional sintering, there is a significant difference in $n$ for microwave sintering. For pressureless sintering, the value of $n(\sim 3)$ suggests that densification is controlled by lattice diffusion. However, this hypothesis conflicts with the consensus that the dominant path for diffusion in the intermediate stage of alumina sintering is along the grain boundary. The question appeared to be what could the electromagnetic field be doing to the sample to produce such apparent changes in the diffusion?

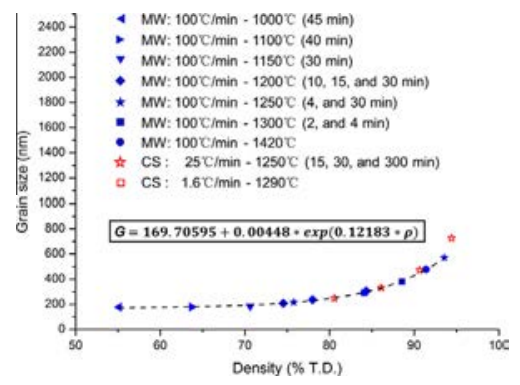

Figure 2. Grain size $(G)$-relative density $(\rho)$ trajectory of microwavesintered (MW) and conventionally sintered (CS) samples. 

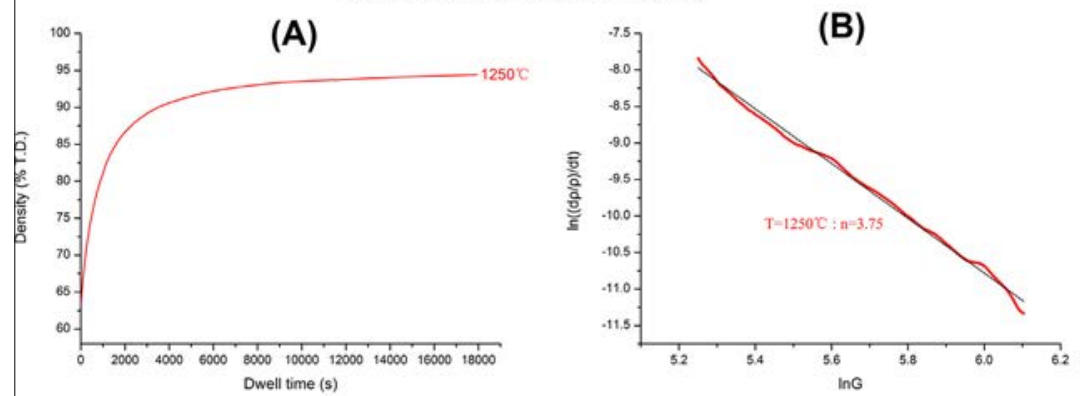

(2) Isothermal microwave sintering
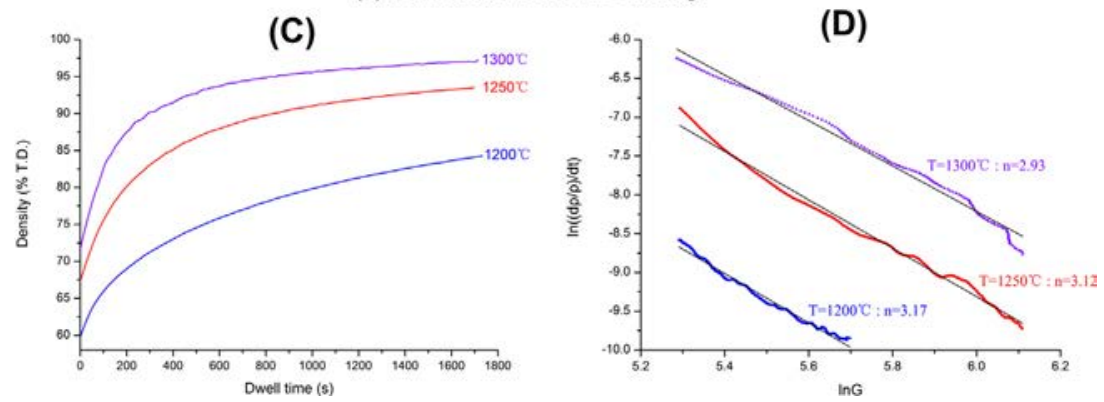

Figure 3. (A and C) Densification behavior and (B and D) kinetics in isothermal sintering of alumina: (1) conventional sintering at $1250{ }^{\circ} \mathrm{C}$; $(2)$ microwave sintering at 1200,1250 and $1300^{\circ} \mathrm{C}$.

Rybakov and Semenov [12] reported that the plastic deformation of the crystal took place as a result of an enhanced vacancy motion caused by a high-frequency electric field in the near-surface layer. This microscopic phenomenon indicates that microwave sintering is similar to pressure-assisted sintering. Elsewhere, Badev et al. [13] suggested that the enhanced sintering behavior of $\mathrm{ZnO}$ in a microwave field is due to the creation of a strength applied on the granular compact. Therefore, in the present work, the densification under a microwave could be considered as pressureassisted sintering. In this way, the value of $n(\sim 3)$ suggests that the grain boundary diffusion mechanism may be predominant throughout densification during the intermediate stage of microwave sintering [10]. The electromagnetic field would lead to an additional force to diffusion, like the application of external pressure to powder compacts, and hence the driving force of densification and densification kinetics are increased.

The microstructural evolution and the densification kinetics in the intermediate stage of microwave sintering of $\alpha$-alumina were investigated. A comparative study was simultaneously achieved in conventional sintering. The results show the difference in the densification mechanisms between these two modes of sintering. Microwaves should provide electromagnetic pressure to powder compacts and result in an additional driving force for sintering and, consequently, in densification kinetics.
Financial support of this work by ANR \#2011 BS08 014 is gratefully acknowledged. The authors also wish to express their gratitude towards Prof. François Valdiviéso at ENSMSE for his help and enthusiasm in the work.

[1] D.K. Agrawal, Curr. Opin. Solid State Mater. Sci. 3 (1998) 480-485.

[2] J. Wang, J. Binner, B. Vaidhyanathan, J. Am. Ceram. Soc. 89 (2006) 1977-1984.

[3] J.P. Cheng, D. Agrawal, Y.J. Zhang, R. Roy, Mater. Lett. 56 (2002) 587-592.

[4] K.I. Rybakov, E.A. Olevsky, V.E. Semenov, Scr. Mater. 66 (2012) 1049-1052.

[5] K.H. Brosnan, G.L. Messing, D.K. Agrawal, J. Am. Ceram. Soc. 86 (2003) 1307-1312.

[6] M.A. Janney, H.D. Kimrey, W.R. Allen, J.O. Kiggans, J. Mater. Sci. 32 (1997) 1347-1355.

[7] F. Zuo, C. Carry, S. Saunier, S. Marinel, D. Goeuriot, J. Am. Ceram. Soc. (2013), http://dx.doi.org/10.1111/ jace. 12320 .

[8] M.I. Mendelson, J. Am. Ceram. Soc. 52 (1969) 443-446.

[9] R.L. Coble, J. Appl. Phys. 32 (1961) 787-792.

[10] S.J.L. Kang, Sintering: Densification, Grain Growth and Microstructure, first ed., Elsevier Butterworth-Heinemann, Oxford, 2005.

[11] Z. Holkova, L. Pach, V. Kovar, S. Svetik, Ceram. Silik. 47 (2003) 13-19.

[12] K.I. Rybakov, V.E. Semenov, Phys. Rev. B 49 (1994) 64 68.

[13] A. Badev, R. Heuguet, S. Marinel, J. Eur. Ceram. Soc. 33 (2013) 1185-1194. 